\title{
Vejetaryen Olmayı Seçmek
}

\author{
ESRA SAHTIYANCI ÖZTARHAN* \\ esraoztarhan@yahoo.com \\ ORCID ID: 0000-0001-6332-5521
}

Öz: Koreli yazar Han Kang Vejetaryen isimli romanına kadın kahraman Yonğhe’nin vejetaryen olmaya karar vermesi ile başlar. Bu kararı onu ve çevresindekileri de etkileyecek bir karardır. En başta sadece yemek seçimleriyle ilgili görünen bu durum, önce kahramanın ailesi ile ilişkilerini etkiler. Daha sonra ise Yonğhe, yemek yemeyi tamamen reddederek kendi kimliği ile ilgili bir karar verir. Oldukça basit gibi görünen yemek yemeyi seçmesi ya da yememeyi seçmesi onun kendini yok etmesine kadar giden süreci de anlatır. Yazar, romanda kadin kahramanın yemek seçimleri üzerinden yemeğin toplumsal cinsiyet rolleri ile olan ilişkisini sorgular. Romanda et yemek erkek egemen düzenin bir metaforudur. Yonğhe de önce et yemeyi reddederek sonra da bedenine alacağı bütün besinleri reddederek sisteme kendi bedeniyle karşı gelir. Böylelikle yemek yeme eyleminin ve seçimlerinin kimlikle olan ilişkisi de anlatılır.

Anahtar kelimeler: Vejetaryenlik, Et yemek, Toplumsal cinsiyet rolleri, Kadın bedeni.

\section{Giriş}

Koreli kadın yazar Han Kang’’n 2016 Uluslararası Man Booker ödülünü almış romanı Vejetaryen, aslında yazarın daha önce yazdığı üç farklı öyküyü birleştirerek ve genişleterek tekrar yazmasından oluşmuştur. 2000'de kısa öykü halinde yazılan eser, 2007'de tekrar başka bir perspektiften yazılarak roman haline getirilmiş, 2016'da da İngilizceye çevrilerek bu ödüle aday gösterilmiştir. Kitap birçok dile çevrilmiş, çok satanlar arasına girmiş ve hatta sinemaya da uyarlanmıştır. Bu makalede esas olarak romana da adını veren ve bağımsız olarak da okunabilen ilk bölüm üzerinde durulacaktır. Han Kang romanda vejetaryenliği erkek egemen düzenin bir metaforu olarak işlemiştir. Romanın kadın kahramanı da bilinçli bir seçim olarak vejetaryen olmayı seçerek ve hatta romanın sonunda yemek yemeyi reddederek ataerkil düzenin, kadını, hayvanlar ve bitkiler gibi ikincil konumda bırakmasını eleştirmiştir. Kitap kendi yiyeceğine karar veren bedeninin tek hâkimi olmak isteyen bir kadın kahraman yaratmıştır.

\section{Yemek ve Toplumsal Cinsiyet Rolleri}

Roman, kadın kahraman Yonğhe’nin öyküsünü vejetaryen olması, daha sonra da yemek yemeyi tamamen reddetmesi üzerinden anlatır. Dolayısıyla yemek yeme ey-

\footnotetext{
* Yrd. Doç. Dr., Ege Üniversitesi, Edebiyat Fakültesi, Amerikan Kültürü ve Edebiyatı Bölümü.
} 
leminin toplumsal cinsiyet rolleri ya da kimlikle olan ilişkisi belirtilmesi gereken önemli kavramlardır. Claude Fischler'e göre yemek, kimlik bilincimizi oluşturan temel taşlarından biridir. Bir insan topluluğunun yemek yeme şekli o topluluğun içindeki toplumsal düzeninin bir göstergesidir. Yemeğin insan topluluklarını hem birleştiren hem de ayıran özelliği bulunur. Yemek, aynı yemekleri yiyenleri birleştirirken, aynı yemekleri yemeyenlerden ayıran bir ögedir ${ }^{1}$. Yemek yemenin kuralları vardır. Bunlar toplumlara, dine, yaşa, zamana, sınıf farklılıklarına, toplumsal cinsiyet rollerine vb. göre değişir. Yemek herkes için, her zaman için ve her yer için farklı anlamlar taşır².

Yemek aynı zamanda güç ilişkilerinin çokça görüldüğü bir alandır. Yemek seçimleri sınıf, ırk, toplumsal cinsiyet rolü, yaş gibi birçok kıstasa göre belirlenir. Kimin neyi, ne zaman yiyebileceği, bu yazılmamış olan kurallarla baskın kültür tarafından belirlenmiştir. Bunun gibi bazı yiyecekler geleneksel olarak bazı dinlere, bazı milletlere, bazı cinsiyetlere aittir. Et de bu yemeklerden biridir. Tarihi ve kültürel olarak et erkeklere ait bir yemektir. Sınıflar arasındaki yeme seçimleri ve yeme pratikleri üzerine yazdığı makalesinde Bourdieu, toplumsal cinsiyet rolleri açısından da yemek seçme farklılıkları olduğundan bahseder. Örneğin balık veya meyve gibi seçimler erkekler için hafif seçimler olarak görülür. Bazı yemekleri yemekteki pratikler, yavaş yenmesi ya da ısırarak yenmesi gibi o yemeğin kadın ya da erkek için uygunluğunu da belirler. Erkek daha çok ve güçlü şeyler yemelidir. Dolayısıyla kadınlara küçük porsiyonlar ve salata gibi yemekler uygunken, et yemekleri erkeklere yakışır ${ }^{3}$. Ayrıca yemeğin hazırlanması ve sunulması da toplumsal cinsiyet rollerinin yansımasıdır. Örneğin kadın yemeği yapan, masayı kurup kaldıran, bulaşık yıkayan rolündeyken erkek oturan ve ona sunulan yiyecekleri yiyen konumundadir ${ }^{4}$. Toplumsal cinsiyet rolleri ve yemek arasındaki ilişki tarihi olarak kurgulanmıştır. Mutfak zaten bu rollere göre belirlenmiştir ve kadının alanıdır. Eğer erkek yemek pişirecekse, erkekliğinin kaybolmayacağına emin olmalıdır, erkeklere özgü şeyler pişirmelidir Aynı şeklide eğer kadın, kadına atfedilen yemek pişirme eylemini reddederse bu onun normal olmadığının bir göstergesidir.

Yemek aynı zamanda da oldukça sembolik bir alandır. Sadece beslenmek için değil belli bazı güç dengelerinin sürekliliğini sağlamak için de gerçekleştirilen bir eylemdir. Bazı yemekler dişil bazıları ise erildir. Bazı yemekler, imgeler cinselliği çağrıştırır. Et erkelere ait bir yemek olduğu için, eril gücü simgeleyen bir göstergedir. Carol J. Adams bunu Etin Cinsel Politikası kitabında şöyle açıklar:

Geleneksel olarak, çalışan erkeğin kuvveti için ete ihtiyaç duyduğu hissedile gelmiştir [sic]. Bu inanışın içinde bir hurafe yatar: Güçlü hayvanların kaslarını yersek biz de güçlü oluruz. Ataerkil kültürün mitlerine göre et gücü arttırır, erkeklik özellikleri erkeksi yiyecekler yiyerek elde edilir ${ }^{5}$.

1 Claude Fischler, “Food, Self and Identity”, Social Science Information, 27 (1988), s.275.

2 Fischler, "Food, Self and Identity", s.288.

3 Pierre Bourdieu, "A Social Critique of the Judgement of Taste", Food and Culture: A Reader. ed., Carole Counihan ve Penny Van Esterik, New York: Routledge, 2013, s.34-35.

4 Bourdieu, "A Social Critique of the Judgement of Taste", s.37.

5 C. J. Adams, Etin Cinsel Politikası: Feminist-Vejetaryen Eleştirel Kuram, çev., G. Tezcan ve M.E. Boyacıoğlu, İstanbul: Ayrınt1, 2015, s.87. 
Aynı şekilde et en değerli yemek olarak da erkeklere layıktır. Kadınlara ise kendi önemlerine yakışan, sebzeler ve otlar düşer. Bunların sembolik gücü etinki kadar güçlü değildir. Adams’a göre etin çağrıştırdıkları ile sebzelerin çağrıştırdıkları da farklıdır. Bitkiler, tadı olmayan tekdüze bir edilgenliği çağrıştırırlar. Bitki yemek aynı bitki gibi olmak yani kadın olmakla eşdeğerdedir". Ayrıca et "Batı kültüründe uzun süredir kadının maruz kaldığı baskının metaforu olarak kullanılagelmiştir”. Adams bunun mitolojideki Metis’i yutan Zeus öyküsünden geldiğini söyler. Adams bu mitin "cinsel olarak arzu edilen objeyi tüketilebilir olarak görmek" sonucunu yarattığını yazar ${ }^{7}$. Erkek egemen kültür şiddetten beslenir.

Romanda kahraman, gördüğü vahşi sahneleri olan bir rüyadan sonra vejetaryenlik kararı verir. Ancak maruz kaldığı vahşet bu rüyalarla sınırlı kalmaz. Öncelikle kocası tarafından "normal" olunmaya zorlanırken hem sözlü hem cinsel şiddete maruz kalır. Ona göre karısının yaptıkları "kocasının düşüncesini yok sayan bir inatçılıktır"8. Kocası onu vejetaryen yapan rüyayla ilgili tek bir soru sormaz ve ilgilenmez bile. $\mathrm{Bu}$ duyarsızlığı, onun içinde bulunduğu travmayı duymak bile istememesi, Yonğhe için adeta başka bir şiddettir. Evde artık et pişmediği için et yiyemeyen kocası iyice sinirlenir. Cinsel arzularına da bir karşılık bulamayınca karısı ile zorla birlikte olur. $\mathrm{Bu}$ tam da Zeus'un Metis'i bir et gibi yemesi, et gibi görmesine benzer bir durumdur. Yonğhe'nin duyguları, davranışları ne olursa olsun kadınlık ve karılık görevlerini yerine getirmelidir. Yoksa erkek egemen toplum zorla onu uyum sağlamaya zorlayabilir.

Yonğhe’nin maruz kaldığg bir başka baskı ise vejetaryen olduğu için kocasının şirketindekiler ve patronla çıktığı yemekte görülür. Yemeğin toplumsal kuralları vardır. Eril güç, yani burada kocasının patronu ve masadakiler, ona ne yiyeceğini söylerler. Farklı olmak, yani herkesin yediğini yememek, tepki çeker ve kabul edilemez. Masadakiler onu yine hiç anlamadan ve dinlemeden yargılarlar: "Et yemeden yaşanabilir mi?", "Etoburluk temel içgüdüdür, yani ot oburluk insan doğasına ters. Normal değil" derler ${ }^{9}$. Bu sosyal baskı da yemek üzerinden bireylere ne yenip yememenin normal olduğunu bildiren bir tür şiddettir. Bireysel kararlara olan bu tepki, sisteme karşı olanlara bir uyarıdır.

\section{Et Yemek ya da Yememek}

Adams da vejetaryen edebiyatında neredeyse her eserde vejetaryenliği seçen bireye karşı saçma sorular soran, onun seçimin kendisine bir meydan okuma gibi gören, seçimini değersizleştiren, önemsiz konularda düşündüğünü hissettiren birileri olduğunu söyler ${ }^{10}$. Han Kang da bir röportajda kendisinin de kahramanla aynı deneyimi yaşadığını yazar. Yirmili yaşlarında vejetaryen olmaya karar verdiğinde çevresinin çok tepki gösterdiğini anlatır. Herkesin ona tekrar et yedirmek için seferber olduğundan bahseder. Yemek masasında "tek et yemeyen olmak" zor bir durumdur.

6 Adams, Etin Cinsel Politikası, s.92-93.

7 Adams, Etin Cinsel Politikası, s.112.

8 Han Kang, Vejetaryen, çev., Göksel Türközü, İstanbul: April Yay., 2017, s.17.

9 Kang, Vejetaryen, s.24.

10 Adams, Etin Cinsel Politikası, s.178-179. 
Bunu da Kore toplumunun kolektif yapısına bağlar ${ }^{11}$. Et yemeyi reddetmek bu bağlamda romanda bireyselliğin de bir metaforudur.

Bir başka sahnede Yonğhe kocasıyla anne babasının evine gelir. Orada kocası karsısının bu "kabul edilemez" durumunu onlara şikayet eder. Bir an önce "normal" kadınlar gibi davranması ve yemesini ister. Asıl şikayet ettiği şey aslında karısının et yemediği için güçsüz düşmesi değil, kocasını "dinlememesidir"12. Bu da ailenin toplumsal düzenin ve ataerkil sistemin bir uzantısı olarak yemek yeme eylemi üzerinden kadınlara nasıl baskı uyguladığına bir başka örnektir. Yonğhe’nin annesi ve kız kardeşi de edilgen oldukları, bu olaylara sessizce şahit kaldıkları için ataerkil sistemin hem bir kurbanı hem de parçasıdırlar. Babası ise kızının durumu kabullenmez ve çok kızar:

Şu andan itibaren vejetaryenlik miymiş neymiş hemen bitiriyorsun. Bunu, bunu hepsini ye hemen. Yokluk içinde de değilsin, bu ne hal yahu?(...) Şu halini görmek yüreğimi yakıyor. Babanın sözünü nasıl dinlemezsin? Ye diyorsam ye! ${ }^{13}$

diyerek kızının yemek seçimine müdahale eder. Hatta babasının bu tepkisi kızına vurmaya kadar uzanır ${ }^{14}$. Kızının bedenine almayı reddettiği eti zorla ağzına sokarak bir çeşit onun bedenine hükmetmek ister. Bu sahneyi de kocası anlatır: "Karımın ağzının açıldığı an kayınpeder eti tıkıştırdı" der ${ }^{15}$. Zaten kayınpederi için sorun olan kızının sağlı̆̆ değil düzene karşı gelmesi, onu dinlememesi, onun istediğini yememesidir.

Bu olaydan sonra şiddet daha da artar ve Yonğhe kendini biçakla keser, yine kocasının ağzından olayın dehşeti anlatılır: "Karımın bileğinden fıskiye gibi kan fışkırdı. Beyaz tabakaların üzerine kırmızı kan yağmur gibi boşandı"16. Bu ve buna benzer et ve kan imgeleri romanda özellikle rüya sahnelerinde çokça görülür. Kang roman boyunca kan ve et imgelerini özellikle kadına uygulanan fiziksel ve psikolojik şiddetin bir yansıması olarak kullanmıştır. Bu imgeler özellikle rahatsız edici şekilde romanda yer alır. Örneğin, Yonğhe'nin sözleri şu şekildedir: "Kendi ellerimle insan öldürme hissi, yahut birisi tarafından öldürülme hissi, yaşamamış olsam kesinlikle hissetmeyeceğim (...) Donuk, yavan, hayal kırıcı. Hafif soğumuş ılık kan gibi”'17. Bir başka rüyasını anlattığı sahnede yine et üzerinden şiddeti anlatır: "Vahşi bir hayvanın görüntüsü, parçalanmış bir kafatası, ardından tekrar vahşi bir hayvanın gözleri”"18.

Bir röportajında yazar: "Şiddet insan olmanın bir parçasıdır ve ben o insanlardan biri olduğumu nasıl kabul edeceğim?” der. Kang, özellikle onu etkileyen ve yazmaya

11 Kry Lee, "Violence and Being Human: A Conversation with Han Kang," World Literature Today, May 2016, s.66.

12 Kang, Vejetaryen, s.27.

13 Kang, Vejetaryen, s.35-36.

14 Kang, Vejetaryen, s.38.

15 Kang, Vejetaryen, s.38.

16 Kang, Vejetaryen, s.39.

17 Kang, Vejetaryen, s.28.

18 Kang, Vejetaryen, s.32. 
yönelten şiddetin gündelik hayatta karşımıza çıkan şiddet olduğunu belirtir. Ona göre: "Et yemek, et pişirmek gibi günlük aktiviteler içinde normalleştirilmiş şiddeti barındırır"19. Bu şiddet ise et simgesi ile birlikte erkek egemen toplumu yansitır. Yani vejetaryen olmayı seçmek bu şiddetin bir parçası olmayı, et ve onu tüketen ataerkil toplumu da reddetmektir. Bu anlamda bir başkaldırıdır.

Cumhuriyet Kitap ekindeki yazarla yapılan röportajda, Kang vejetaryen kelimesini "bir şeyi reddeden" anlamında kullandığını söyler. Romanın son bölümünde kahramanın ancak ağaç olmaya çalışarak sisteme karşı geldiği görülür. Kadınlardan beklenilen, toplumda normal sayılan davranış biçimleri edilgen olmak, ona biçilen rollere boyun eğmek ve kabullenmektir. Aynı Emily Dickinson'ın şiirinde dediği gibi:

Çılgınlık en güzel akıldır

Görmesini bilen göze,

Akılsa zırdelilik -

Bunda da her şeyde olduğu gibi

Çoğunluk ağır basar

Kabullen - akıllisındır

İtiraz et - tehlikelisin

Zincirlere vurulacak $\operatorname{kadar}^{20}$.

Romanda da kahramanın akıl sağlığının bozulması, kadının eğer toplumsal rolleri reddederse, deli ya da çılgın etiketiyle damgalanacağına bir örnektir. Romanın son bölümünde Yonğhe’nin artık iyice akıl sağlı̆̆ını kaybettiği, akıl hastanesinde bir parça yemeği ve suyu bile reddettiğinden yaşamsal faaliyetlerinin iyice durduğu görülür. Yaşamsal faaliyetlerinin durması bir yandan yemek yemeği reddetmesindendir. Bir yandan da artık dayanamadığı ataerkil düzene ve baskıya bir tepki olabilir. Yonğhe gerçekten akıl sağlığ 1 yerinde olmadığı için değil de artık yaşamak bile istemediğinden akıl hastanesinde olabilir. Ancak romanın bütününde gerek anlatıcılar tarafından gerekse rüyalarla verilen ayrıntılar, bu delirmiş olma durumunun, deliliğin metaforik olduğunu ispatlar. Yonğhe’nin kendi dünyası, seçimi, hayatı algılayışı toplumdan farklıdır; bu da başkaları için delilik demektir. Zaten Yonğhe'nin, toplumun beklentilerine cevap vermediği ve öyküsü de kendisi değil de başkaları tarafından yazıldığı için deli olarak etiketlenmesi de olasıdır.

Kadın ve erkeğin birbirinden tamamen farklı özleri olduğunu savunan esasçı görüşe göre, rasyonel olan, mantıklı olan normal olanı yapan erkeklerken, kadın irrasyoneldir. Romanda da kadın kahramana çevresi tarafından yöneltilen suçlamalar, "saçmalamaması" için yapılan uyarılar hep bu ikili karşıtlığın bir sonucudur. Eşinin vejetaryenliği seçmesi üzerine kocası baskın kültürdeki çoğu insanın düşüncelerine tercüman olur:

Son günlerde vejetaryenlik furyasının yaygın olduğunu görüp duyuyordum. Sağlıklı, uzun yaşamak düşüncesiyle, alerji gibi şeylerden kurtulmak yahut

19 Lee, "Violence and Being Human: A Conversation with Han Kang", s.65.

20 Emily Dickinson, Rütbesi Yalınayak: Emily Dickinson Şiirlerinden Seçmeler, çev., Ayşe Lahur Kırtunç, Ankara: Efil Yayınevi Yay., 2009, s.52. 
çevreyi korumak için insanlar vejetaryen oluyor. Elbette Budist tapınağındaki keşişler hayvanlara zarar vermemeyi amaçlar ve hayatlarını bunun üzerine kurar, ancak ergenlik dönemindeki kızlar bile bu kadarını yapmıyor. Kilo verme, hastalıktan kurtulma, kötü bir ruh tarafından esir alınma, uykunun hazımsızlıkla bölünmesi gibi sebeplerden yeme alışkanlığ 1 değiștirilebilir de bir kâbus görüp et yemeyi bırakmak anlaşıllamaz ${ }^{21}$.

Buna karşı gelmek kadınlığa atfedilen "delilik, histerik olma" gibi etiketlenmelerle sonuçlanır. Kocaya, babaya ve ataerkil düzene karşı gelmek kabul edilemez. Vejetaryenlik da bu anlamda kadına toplumda atfedilen rollerin reddedilmesi olarak okunabilir. Kocası Yonğhe için şöyle der: "Bu denli bencil ve kendi kafasına göre takılan bir yönü olduğuna inanamıyordum. Demek ki böyle anormal bir kadındı"22. Romanda vejetaryen olmayı seçtikten sonra bir eş olarak eşine yemek yapmadığı ya da Yonğhe’nin ütü ütülemediği görülmektedir. Kocasına "bedeninden et kokusu geliyor" diyerek onunla beraber olmayı da reddeder ${ }^{23}$. Dolayısıyla yemekle ve beslenmeyle ilgili bir seçim olarak görülen vejetaryenlik bütün kadınlık sorumluluklarından da vazgeçiş ve toplumsal cinsiyet rollerine bir karşı koyuştur. Yonğhe'nin bu seçimden sonra sutyen giymeyi reddetmesi, bazen çıplak dolaşması kıyafetlerine ve temizliğine özen göstermemesi de buna bir başka örnektir. Bu aynı zamanda toplumsal kurallara bir başkaldırıştır.

\section{Yemek ve Kadın}

Edebiyatta ya da popüler kültürde çoğu zaman kadınlar hayvanlarla özdeşleştirilir. Eko feministlerden, hayvan çalışmaları kuramcılarına birçok kuramcı toplumda kadın ve hayvanların benzer şekilde değersiz olduklarından bahseder. Eko feministlere göre ikili karşıtlıklardan hayvan ve insan gibi benzer bir ilişki kadın ve erkek arasında vardır ve bu ikili karşıtlık da benzer güç ilişkileri barındırır. Bu kuramlar, her iki grubun da yani hayvanlar ve kadınların da baskın kültürün hegemonyası altında olduklarını bu yüzden seslerinin çıkmadığı ve tek tipleştirmeye maruz kaldıklarını anlatır. Gökçen, Amerikan edebiyatındaki hayvan çalışmaları ile ilgili kitabının giriş bölümünde birçok kuramcıdan örnek vererek bunu inceler. Toplumda hem kadınlara hem de hayvanlara karşı şiddetin, onları bilimsel ya da cinsel obje olarak görmenin bu "şeyleştirme" politikasına hizmet ettiğini söyler ${ }^{24}$.

Anlatım stratejisi olarak romandaki üç bölüm farklı anlatıcılar tarafından yazılmıştır. İlk bölüm, Vejetaryen Yonğhe adındaki kadının kocası tarafından anlatılır. İkinci bölüm olan Moğol Lekesi’ni, kadının kız kardeşinin kocası anlatmıştır. Üçüncü ve son bölüm olan Alev Ağacı'nın anlatıcısı ise Yonğhe'nin kız kardeşidir. Dolayısıyla romanın kahramanının öyküsü ailedeki diğer insanlar tarafından anlatılır. Kahramanın kendi sesi yoktur. Hep başkalarının gözünden görüldüğü şekilde var olur. Romanda Yonğhe'nin sesi ancak italik halde yazılan, rüyalarını anlattığı bölümlerde

21 Kang, Vejetaryen, s.17. 
ya da geçmişi anlattığı bölümlerde anlatıyı keser ve duyulur.

Carol J. Adams da Etin Cinsel Politikası kitabında kadın ve hayvanların edilgenliğini ve baskı altında bulunma durumlarını verdiği popüler kültür imgeleri ile anlatır. Ona göre pornografideki zincir, ip, kamçı gibi araçlar aynı hayvanlara hükmetmeyi çağrıştırır. Hayvanlara yapılan kötü muamele ile kadınlara şiddet uygulama birbirini andırır ${ }^{25}$. Baskın kültür hem kadınları hem hayvanları nesneleştirir. Adams'a göre kadınlara tecavüz edilmesi de hayvanların kesilmesi ile aynı değersizleștirmeye örnektir ${ }^{26}$. Yani kadınlara da aynı yenilecek et parçaları gibi davranılır. Bu durum romanda bedeni kocası tarafından cinsel ihtiyaç için kullanılan, sanatçı akrabası tarafından palet olarak kullanılan, akıl hastanesindeki doktorlar tarafından sanki bir deney faresiymiş gibi saygısızca kullanılan, zorla ilaç içirilen kadın kahraman örneğiyle görülür. Yonğhe’ye roman boyunca insanların hayvanlara, cansız bir nesne ya da önemsiz bir canlıymış̧̧asına davrandıkları gibi saygısızca ve vahşice davranılır. Ne yemek istediği ya da yemek istemediği de bu yüzden önemli değildir.

Kadınların toplumda güçsüz bırakılmasının sembolü çoğu zaman et ve kan imgesidir. Kadınlar da hayvanların kesilmesi ve yenilecek et haline getirilmeleri gibi, ataerkil toplum tarafından duygusal ve fiziksel açıdan paramparça edilebilirler. Bu anlamda romandaki kahramanın gördügü rüyalardaki et yeme, kesilen hayvan imgeleri aslında kadınlara uygulanan baskının ve şiddetin bir yansımasıdır. Yonğhe gördüğü bir rüyayı şöyle anlatır:

Yüzlerce, büyük ve kıpkırmızı et parçası upuzun bambu çubuklara asılı. Bazılarından kırmızı kan yere damlamakta hâlâ. Bitmek bilmeyen et parçalarını geçiyorum ama karşı tarafta bir çıkış yok. Üzerimdeki elbise tamamen kanla ıslanıyor (...) Ellerime kan bulaşmış. Ağzıma kan bulaşmış. O ahırda, yere düşen bir et parçasını yemişim çünkü. Yumuşak çiğ eti diş etlerimde ve damağımda gezdirip kanı emmişim. Ahırın zeminindeki kan birikintisine yansıyan gözlerim işıldamışs ${ }^{27}$.

Yonğhe de geçmişte yediği etin kendinin bu ataerkil sistemdeki varlığını sorgulamasına engel olduğunu düşünür. Ne zaman ki et yemeyi bırakır, o zaman bu sistemin kanayan hayvanlar gibi acı çeken kadınların ait olduğu bu sistemin dışına çıkabilir ancak. Romanın başka bir yerinde Yonğhe yine yemek yemeyi reddedişinin sebebini artık nefes alamamak olarak anlatır. Göğsünde biriken etler yüzünden nefes alamıyorum der: "Çok fazla et yedim. O hayatlar bozulmadan orada asılı. Kesinlikle. Kan ve etlerin hepsi sindirilip vücudumun her köşesine yayılmış, tortusu dışarı atılmıştır, ama o hayatlar ısrarla karın boşluğuma yapışmış duruyor (...) Kimse tekrar nefes almamı sağlayamaz"28. Romanda vücudunu ölü hayvanlardan oluşan bir mezar gibi görür.

Bazen de kadın olma durumu bir bitkiye benzetilir. Vejetaryen romanının fikri as- 
lında ilk defa yazarın 2000 yılında yayınladığı "Fruits of My Woman" adlı kısa bir öykü ile atılmıştır ${ }^{29}$. Bu öykü, eve geldiğinde karısının bir ağaca dönüştüğünü gören bir adamla karısının öyküsüdür. Kocası kadına bir bitki gibi bakar, sular. Kadın daha sonra tohum bile verecek kadar gerçek bir bitki gibi olur. Vejetaryen romanının sonunda öğrendiğimiz kadın kahramanın aslında bir ağaca dönüşme isteği ve çabası da benzer bir temadır. En baştan beri okuyucunun şahit olduğu toplumsal düzene direniş ve vejetaryenlik seçiminin son aşaması ise bir bitkiye dönüşerek bedeni bütün bu baskılardan kurtarıp özgürleşmenin son aşamasına geçmektir. Ayrıca ikinci bölümde yer alan kardeşinin sanatçı kocasının onun bedeninin bir tuval gibi kullanarak yaptığı yaprak ve çiçek motifleri de bu aşamaya geçileceğinin bir habercisidir adeta. Yonğhe'nin çıplak bedeni yeşil doğanın bir parçası olunca toplumsal rollerden ayrılmış hale gelir. Ama bu onun için hâlâ yeterli değildir. Doğanın gerçekten bir parçası olmak istemektedir: "[D] ünyadaki bütün ağaçlar kardeşim gibi” der ${ }^{30}$. Artık kadın olmaktan, yani kadını baskılayan toplumsal cinsiyet rollerinden ve ataerkil baskıdan kurtulur. Zaten çok zayıfladığı ve güçsüz düştüğü için de görüntüsü kadın gibi değildi. Romanda birçok yerde göğüslerinin iyice küçülmesine vurgu yapılması da artık cinsellikten, doğurganlıktan öte bir varlığa ve bedene dönüşüyor olduğunu göstermek içindir:

Vücudumda yapraklar yeșeriyordu, ellerim kök salıp (...) toprağın altına uzanıyordu. Durmaksızın, durmaksızın (...) Kasıklarımda çiçekler açmaya çalıştı̆̆ için bacaklarımı açtım (...) Ben sulanmalıyım abla, bana böyle yemekler gerekmiyor. Benim suya ihtiyacım var ${ }^{31}$.

Yonğhe ağaç olmakla bir yandan toplumsal baskıdan ve ataerkil toplumdan kurtulur, ama bir yandan da yine ikincil bir role bürünür. Eko Eleştiri: Çevre ve Edebiyat kitabının eko feminizmle ilgili bölümünde kadın ve doğa ilişkisi şöyle anlatılır:

Her kültür, kadınları onların değerini alçaltan veya değerini olduğundan daha düşük gösteren bir sembolle özdeşleştirmiştir. Bu tasvire uyan bir tek sembol vardır, o da genel anlamıyla doğadır (...) zira doğa ikincildir, tıpkı kadın gibi ${ }^{32}$.

$\mathrm{Bu}$ da Batı’nın kurduğu ikili karşıtlıklardan başka biridir. Ekofeministler aynı zamanda hem kadınlar hem doğa üzerine kurulan hâkimiyete ve şiddete aynı şekilde karşıdırlar. Aynı zamanda "ataerkil esasçllı̆̆a dayanan görüşe meydan okur ve sözde erkeksi özelliklerin insanın doğasında olmadığını ve güç ilişkilerinin gerekli olmadığını savunurlar" ${ }^{\prime 3}$. Bu hareket dolayısıyla erkek egemen kültüre karşı bir harekettir. $\mathrm{Bu}$ kültürün yücelttiği saldırganlık, güçlü olma hallerinin de bir eleştirisidir. Kang da romanında et ile bağdaştırdığı vahşet ve ataerkil kültüre karşı doğayı bir kurtuluş aracı olarak koyar.

29 Lee, "Violence and Being Human: A Conversation with Han Kang”, s.66.

30 Kang, Vejetaryen, s.124.

31 Kang, Vejetaryen, s.127.

32 Pelin Kümbet, “Ekofeminizm: Kadın, Kimlik ve Doğa”, Ekoeleştiri: Çevre ve Edebiyat, ed., Serpil Opperman,

Ankara: Phoenix, 2012, s.177.

33 Kümbet, "Ekofeminizm: Kadın, Kimlik ve Doğa”, s.190. 


\section{Yemek ve Kimlik}

Yemek hem çok toplumsal ve ideolojik hem de çok bireysel bir alandır. İnsanoğlu yediği veya yemediği yemeklerle biyolojik, fizyolojik ve sosyal olarak kendini kurgular $^{34}$. Yemek onu yiyeni gerçekleştirir. Kişinin yedikleri kadar yemedikleri de onun kim olduğunu belirleyen başka bir olgudur. Romanda et yemeyi reddetmesi ile Yonğhe yepyeni bir kimliğe bürünmek ister. Yonğhe'nin yeme eylemini dereceli olarak reddetmesinin ardında insanlığa ve erkek-egemen insanlığa bir tepki yer almaktadır. Kadının bedenine almak istediği ya da bu durumda istemediği besin bile başkalarının kontrolü altındadır.

Aslında yemek yemeyi reddetmek, yani kadının kendi kararlarını veriyor olması, bir güçlenme olduğu için tepki görür. Adams bu durumu "muhalifliğin yemekle dile gelmesi” olarak yorumlar. Ona göre:

Kadınlar Batı kültüründe yemeğin hazırlayıcısı olduğuna göre, et de erkek yiyeceği olarak tanımlandığına göre, vejetaryenlik kadın dili içerisinde susturulmuşluğundan kaçmak isteyen bir anlam ifade ediyor olabilir (...) [B] u durumda kadın bedenleri, kadınların vejetaryenlik aracılığıyla muhalifliklerini kazıdıkları metinlere açık hale gelir ${ }^{35}$.

Kendi bedenine ne alacağına karar veremeyen ve yine bedeni üzerine resim çizilecek bir tuval gibi kullanılan Yonğhe için bu daha da önemlidir. Kadının bedeninin hep başkalarının izlerini bırakacağı edilgen bir yüzey haline gelmesi romanda da hep belirtilir. Ancak vejetaryenlikle ve daha sonra yemeyi reddetmekle, kendi istediklerini giymek veya çıkartmakla, Yonğhe bu edilgen duruma dur diyebilmektedir.

Bordo ise anoreksiya nevrosayı incelediği makalesinde yüzyıllar boyunca kadın bedeninin ataerkil kültürde tıptan, modaya kadar birçok alanda güç ilişkilerinin kurbanı olduğunu söyler ${ }^{36}$. Dolayısıyla kadının bedenini özgür kılması, kendi istediği gibi sosyal baskılardan ayrı tutması oldukça zordur. Ancak kendi bedeni üzerinde kontrol kurabilmesi ile sisteme başkaldırabilir anoreksik hastalarda görülen her türlü besini reddetme bazen bireyin bedenine hükmetmesinin tek yolu olarak okunur ${ }^{37}$. $\mathrm{Bu}$ haliyle politik bir duruş, bir karşı geliştir. Aynı şekilde Kang 'in romanında da Yonğhe için tek kontrol edebileceği alan kendi bedeni üzerine verebileceği kararlardır. Bunun gençliğinden beri ne kadar zor olduğu görülse de yaşadığı yemek seçimi ile başlayan geri dönülmez bir karşı koyuştur.

Romanın en sonunda yemeyi bilinçli olarak reddettiği ve canının son damlasına kadar direndiği için elinden bir şey gelmeyen ablası ona, "En çok zarar verebileceğin şey senin kendi bedenin. Kendi istediğin şekilde yapabileceğin tek şey bu. Ancak bu

34 Fischler, "Food, Self and Identity", s.275.

35 Adams, Etin Cinsel Politikası, s.304.

36 Susan Bordo, “Anorexia Nervosa: Psychopathology as the Crysatllization of Culture”, Cooking, Eating, Thinking: Transformative Philosophies of Food, ed., Deane W. Curtin ve Lisa M. Heldke, Bloomington: Indiana UP, 1992, s.31.

37 Bordo, “Anorexia Nervosa”, s.38. 
bile istediğin gibi olmuyor (...)" diyerek verdiği savaşın zorluğuna dikkat çeker ${ }^{38}$. Yonğhe’nin de kendi bedenine girecek besinlerden, ona dokunacak kişilere kadar en özgür olması gereken kararları bile almasına izin vermeyen bu sistemde kadın olmaktan çıkıp, yok olup, ağaç olmaktan başka yolu yoktur.

\section{Sonuç}

Kang'n Vejetaryen romanı kadının toplumdaki yerini, yediği ya da yemediği yemek üzerinden incelemiştir. Toplumdaki güç ilişkilerinin yemek alanında kendini göstermesine örnek olacak bu romanda kadın istediği yemeği seçecek güce bile sahip değildir. Romanın kahramanının et yemeyi reddetmesi bu anlamda uygulaması güç bir karardır. Yonğhe eti erkek egemen kültürün bir yansıması olarak görür. Aynı zamanda et ve et yemek kendisinin de çocukluğundan beri hem babası hem de kocasından gördügü şiddetin bir metaforudur. Böylelikle et yemeyi reddetme sadece besinsel öneme sahip, sağlık için verilmiş bir karar değil, ataerkil sistemi reddediş olarak okunabilir. Romanda kadın kahraman kendisini hem hayvanlarla hem bitkilerle özdeşleştirerek, kadınların aynı bu varlıklar gibi toplumda güçsüz ve edilgen olmalarını eleştirir. En sonunda kahramanın hiçbir şey yemeyerek bedeninin yemeye tamamen kapaması, bir ağaç olma istemesi yani toplumsal baskılardan tamamen bedeninin arındırması anlamına gelir. Yemek reddetmek, bedenine hâkim olmak oldukça özgürleştirici bir konumdur.

\section{Kaynakça}

Adams, C. J. Etin Cinsel Politikası: Feminist-Vejetaryen Eleştirel Kuram. Çev., G. Tezcan ve M.E. Boyacioğlu. İstanbul: Ayrıntı, 2015.

Bordo, Susan. "Anorexia Nervosa: Psychopathology as the Crysatllization of Culture". Cooking, Eating, Thinking: Transformative Philosophies of Food. Ed. Deane W. Curtin ve Lisa M. Heldke. Bloomington: Indiana UP, 1992: 28-56.

Bourdieu, Pierre. "A Social Critique of the Judgement of Taste". Food and Culture: A Reader. Ed. Carole Counihan ve Penny Van Esterik. New York: Routledge, 2013: 31-39.

Dickinson, Emily. Rütbesi Yalınayak: Emily Dickinson Şiirlerinden Seçmeler. Çev., Ayşe Lahur Kırtunç. Ankara: Efil Yayınevi Yay., 2009.

Fischler, Claude. "Food, Self and Identity". Social Science Information. 27 (1988): 275293.

Gökçen, Nilsen. Encountering the Animal: Exploration in American Literature. İstanbul: Boyut Yay., 2015.

Kang, Han. Vejetaryen. Çev., Göksel Türközü. İstanbul: April Yay., 2017.

Kümbet, Pelin. "Ekofeminizm: Kadın, Kimlik ve Doğa". Ekoeleştiri: Çevre ve Edebiyat. Ed. Serpil Opperman. Ankara: Phoenix, 2012: 171-206.

Lee, Kry. "Violence and Being Human: A Conversation with Han Kang". World Literature Today. Mayıs 2016. 
İNSAN\&İNSAN, Y11/Year 5, Say1/Issue 15, Kış/Winter 2018, 64-74

e-ISSN: 2148-7537, www.insanveinsan.org

\title{
Choosing to be Vegetarian
}

\author{
ESRA SAHTIYANCI ÖZTARHAN
}

\begin{abstract}
Han Kang's novel Vegetarian is the story of a woman heroine who refuses to eat meat and choses to be a vegetarian in medias res. This choice of her would be affecting not only her but also the people beside her. This situation at first seems like a personal choice. However the outcomes would also be affecting her relationship with her family as well. As the novel progresses, she who refuses to eat anything which would lead to her destruction. The novel questions the relationship between food consumption, food choices and gender roles. Meat consumption is regarded as a metaphor of the patriarchal system throughout the novel. Therefore, the woman heroine Yonğhe refuses the system and challenges with her own body. This way the novel analyses the act of eating and choosing food and its relation with identity.
\end{abstract}

Keywords: Vegetarianism, Meat consumption, Gender roles, Women's body. 